\title{
A Survey on the Challenges of Impacts on Applying for a Job in Ho Chi Minh City
}

\author{
Dan Thanh Do \\ Ho Chi Minh City University of Food Industry, Vietnam \\ Email:danthanh0509@gmail.com
}

\begin{abstract}
In the 4.0 context, machines gradually replace humans in most fields. The job market becomes depleted in inverse proportion to the abundant human resources. With hundreds of thousands of people unemployed each year, the rate of competition for job vacancies increases accordingly. Countless impacts decline the performance rating, causing fatal flaws that lead to a poor impression on the employers. Employers will receive countless Curriculum Vitals (CVs) to choose from for a job vacancy. How to surpass the competition and catch the eye of employers? This survey was conducted to discover and analyze the difficulties of applying for a job besides participating in a job interview in Ho Chi Minh City. Besides, the author wants to provide a comprehensive insight into recruitment and human resources in this city. A total of 125 candidates were selected from different professions in Ho Chi Minh City to collect information for this survey. Information collected from the questionnaires consisting of 11 small questions was coded and analyzed quantitatively. The final analysis pointed out the objective and subjective factors affecting the application process. In addition, the psychological abnormality affecting the ability to communicate in answering the interviewers' questions was an outstanding result in the survey. Due to these factors, most of the candidates were rejected from job vacancies. Employers in Ho Chi Minh City consider human resources with a lot of working experience and relationships as an advantage. The goal of this survey that aims to aid candidates in awareness of their problems enhances the success rate in conquering employers.
\end{abstract}

Keywords: job, application, job interview, human resource, recruitment, candidate, staffing, employment

\section{Introduction}

Nowadays, enterprises have demanded stricter requirements in recruitment and selection. Recruitment and selection is a fundamental activity in Human Resource Management. Dan Schawbel (2012) stated that "The reason why recruiting is so powerful is that if you don't bring in the right talent, the other HR functions suffer". It is assisted in finding and contacting to match talented into the enterprises. Under the pressure of industrialization and modernization, the support of machines is increasing in the operation of the organization. "Both the economy and society depend on ensuring that individuals are prepared for the future and remain employable. But people change more slowly than technology. As technology affects jobs and the skills required to perform those jobs, we must all adapt." (Strack, et al., 2019). Machines gradually replace humans in most jobs. Technology advancement not only assists humans in completing tasks more quickly, but it also runs automatically without the need for humans operation. Therefore, the global competition for human resources is increasing along with difficulties in convincing employers.

This competition is not only occurring more somber in Vietnam, especially in Ho Chi Minh City, but also in the world. It is difficult for candidates who graduated with a bachelor's degree to get into a job vacancy.

Applying for a job is a self-accumulating soft skill that very few courses provide detailed instructions for successful practical application. "The real issue is that job searching skills are not taught in schools." (Wolfgang, 2016). This dissertation lists out the detailed causes of job 
application failure. Instead of tips, the causes are given so that candidates can acknowledge their fault and then overcome obstacles. Content is exploited in two main directions. It includes internal and external factors that can make candidates break the impression of employers.

\subsection{The internal factors}

The first direction mainly digs into the factors that are made of psychology, physical, and intelligence quotient (IQ). Problems are developed based on the importance of professional knowledge and necessary skills.

\subsection{The external factors}

The second direction analyses the objective factors that directly affect the judge's assessments. The impression of the interviewers belongs to interview costume, curriculum vitae $(\mathrm{CV})$, nonverbal gestures, and relationships.

\section{Literature Review}

Several past kinds of researches have investigated the issues affecting the job application process. The psychological expressions of candidates such as anxiety, weak knees, and sweaty palms were measured by MASI. It is referred to as the Measure of Anxiety in Selection Interviews (McCarthy \& Goffin, 2004). The nervous expressions of candidates in job interviews were continuously assessed and remedied before they appear to interviewers. This research also provided reasons why anxious interviewees receive lower interview performance ratings (Feiler \& Powell, 2015; Feiler \& \& Powell, 2013). Another research showed rules and emotional control in a job interview through evaluating the videotaped performance of graduates (Sieverding, 2009).

These researches mainly focus on the negative emotions and psychological pressures of candidates during the job interview. The present survey entirely synthesizes the content of these above researches and broadens the issues which have not been mentioned. Psychological pressures are expressed not only through anxiety, weak knees, or sweaty palm but also in voice tone, confidence, hesitation with awkward questions of interviewers, and so on.

Considerable research (Hall, Wildgen, \& Sherman, 1980) was conducted to portray gender, physical, and IQ discrimination. Participants included six retarded adults who were taught job application and interview skills. The final result demonstrated these participants were able to use what they have learned in applying for "real" jobs. Unfair discrimination in employment against the retarded continues unceasingly.

The appearance had a significant effect on interviewers' selection decisions. Some of researches (Forsythe, Drake, \& Cox, 1985) (Spinks \& Wells, 1999) (Behrend, Toaddy, Thompson, \& Sharek, 2012) (Piopiunik, Marc; Schwerdt, Guido; Simon, Lisa; Ludger Woessmann, 2018) described how to impress interviewers through the avatar, curriculum vitae $(\mathrm{CV})$, résumés, job application letters, and costume.

The present survey overturns the issues and indicates wrong impressions that lead to being rejected among competitors. In addition, this survey evaluates and compares the level of the factors affecting candidates and the criteria that most influence the selection decision of the employers. 


\section{Research Method}

\subsection{Participants}

Subjects were selected from candidates in three groups of university students, graduate students, and service professionals. These candidates belong to all professions and have applied for a job in Ho Chi Minh City. A total of 125 candidates took part in answering the online questionnaires. In which, the number of participants was $60.7 \%$ in women and $38.5 \%$ in men, the rest are other genders. Thirty candidates are graduate students and service professionals out of the total number of participants. Their professions are mostly English linguistic, automation technology, business administration, logistics, etc.

\subsection{Design}

The design of the present survey was questionnaires made up of 11 small questions, including two personal information requests. There are three types of questions used in this design: yesno questions, multiple-choice questions, and rating scales from 1 (very low) to 5 (extremely). The content is mainly what affects the job interview process, the impression and selection criteria of employers that candidates evaluate the most important.

\subsection{Procedure}

These questionnaires were designed online in Google Form. The author delivered each questionnaire to each participant as a link through mail and social network. After participants had outright completed the questionnaires, the answers would be automatically sent to the designer's Google Form library.

\subsection{Assessment and Measure}

Based on the quantitative method, the procedure for collecting information was conducted to evaluate and compare directly some problems that candidates have had in job application experiences. Data is encrypted and analyzed by SPSS software base using chart types such as pie charts, bar charts, histograms, frequency tables, and comparing means, correlate, regression.

\section{Findings and Discussions}

\subsection{Findings}

\subsubsection{Psychological pressures}

Figure 1. The percentages of candidates have problems in job interview

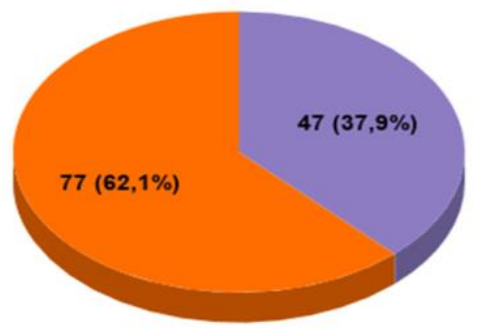

No problems - Had problems 
According to the data collected, the percentages of these challenges in the interview process are established using a bar chart. Out of the total participants, $62.1 \%$ have had problems in Figure 1. The number of participants with any difficulties in the job interview is more than twice that of participants without.

Figure 2. The percentages of challenges during a job interview process

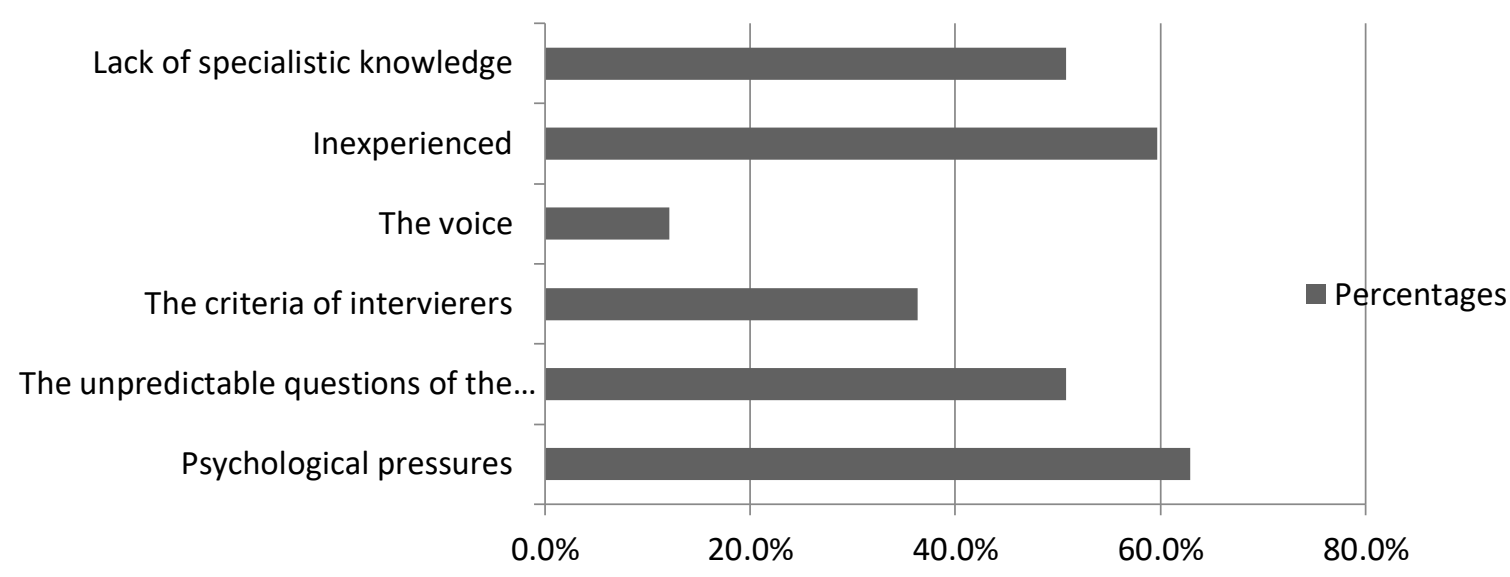

Survey has found the biggest problem that candidates in Ho Chi Minh City face during a job interview are dues to psychological pressure. The bar chart in Figure 2 illustrates the disproportion of challenges affecting the interview performance of candidates. The highest percentage is psychological pressure at $62.9 \%$.

4.1.2 The influence of psychological pressure on the voice

Table 1. Correlations

\begin{tabular}{|c|c|c|c|c|c|c|}
\hline & & CL1 & CL2 & CL4 & IP1 & IP4 \\
\hline \multirow[t]{3}{*}{ CL1 } & Pearson Correlation & 1 & .108 & .074 & $.206^{*}$ & .154 \\
\hline & Sig. (2-tailed) & & .231 & .412 & .022 & .088 \\
\hline & $\mathrm{N}$ & 124 & 124 & 124 & 124 & 124 \\
\hline \multirow[t]{3}{*}{ CL2 } & Pearson Correlation & .108 & 1 & .062 & .100 & .078 \\
\hline & Sig. (2-tailed) & .231 & & .492 & .271 & .391 \\
\hline & $\mathrm{N}$ & 124 & 124 & 124 & 124 & 124 \\
\hline \multirow[t]{2}{*}{ CL4 } & Pearson Correlation & .074 & .062 & 1 & -.014 & -.060 \\
\hline & Sig. (2-tailed) & .412 & .492 & & .873 & .510 \\
\hline
\end{tabular}




\begin{tabular}{lll|l|l|l|l}
\hline \multicolumn{1}{l}{ N } & 124 & 124 & 124 & 124 & 124 \\
\hline IP1 & \begin{tabular}{l} 
Pearson Correlation \\
\cline { 2 - 6 }
\end{tabular} & $.206^{*}$ & .100 & -.014 & 1 & $.802^{* *}$ \\
\hline $\begin{array}{l}\text { Sig. (2-tailed) } \\
\text { N }\end{array}$ & .022 & .271 & .873 & & .000 \\
\hline IP4 & 124 & 124 & 124 & 124 & 124 \\
\hline & $\begin{array}{l}\text { Pearson Correlation } \\
\text { Sig. (2-tailed) }\end{array}$ & .154 & .078 & -.060 & $.802^{* *}$ & 1 \\
\hline $\mathrm{N}$ & 124 & 124 & 124 & 124 & 124 \\
\hline
\end{tabular}

*. Correlation is significant at the 0.05 level (2-tailed).

**. Correlation is significant at the 0.01 level (2-tailed).

Table 1 represents correlations among psychological pressures (CL1), communication skills (IP1), and ability to answer questions (IP4). The data after analysis showed that psychological pressures and communication skills have a linear correlation (Sig. $\alpha=0.022 ; \alpha<0.05$ ). Results indicated the common expressions of psychological pressures were not only anxiety, weak knees, sweaty palms (McCarthy \& Goffin, 2004) but also nervous changes in the voice.

\section{Table 2. ANOVA ${ }^{\mathbf{a}}$}

\begin{tabular}{|c|c|c|c|c|c|c|}
\hline Model & & Sum of Squares & df & Mean Square & $\mathrm{F}$ & Sig. \\
\hline \multirow[t]{3}{*}{1} & Regression & 1.466 & 2 & .733 & 3.899 & $.023^{b}$ \\
\hline & Residual & 22.751 & 121 & .188 & & \\
\hline & Total & 24.218 & 123 & & & \\
\hline
\end{tabular}

a. Dependent Variable: RR4

b. Predictors: (Constant), IP4, IP1 
Table 3. Coefficients ${ }^{\mathrm{a}}$

\begin{tabular}{|c|c|c|c|c|c|c|c|c|}
\hline \multirow[b]{2}{*}{ Model } & & \multicolumn{2}{|c|}{$\begin{array}{l}\text { Unstandardized } \\
\text { Coefficients }\end{array}$} & \multirow{2}{*}{$\begin{array}{l}\text { Standardized } \\
\text { Coefficients } \\
\text { Beta }\end{array}$} & \multirow{2}{*}{ t } & \multirow[b]{2}{*}{ Sig. } & \multicolumn{2}{|c|}{$\begin{array}{l}\text { Collinearity } \\
\text { Statistics }\end{array}$} \\
\hline & & $\mathrm{B}$ & Std. Error & & & & Tolerance & VIF \\
\hline \multirow[t]{3}{*}{1} & (Constant) & 1.687 & .133 & & 12.653 & .000 & & \\
\hline & IP1 & .172 & .062 & .407 & 2.755 & .007 & .356 & 2.806 \\
\hline & IP4 & -.157 & .063 & -.367 & -2.483 & .014 & .356 & 2.806 \\
\hline
\end{tabular}

a. Dependent Variable: RR4

Similarly, a statistic also shows a linear correlation between communication skills and the ability to answer questions (Sig. $\alpha=0.000 ; \alpha<0.005$ ). Tables 2 and 3 describe the impact of communication skills (IP1) and the ability to answer questions (IP4) on the cause of exclusion (RR4). The displayed parameters are composed of Sig. Regression $(\alpha \mathrm{R}=0.023 ; \alpha \mathrm{R}<0.05)$, Sig.t (IP1) $(\alpha \mathrm{t}=0.007, \alpha \mathrm{t}<0.005)$, Sig.t (IP4) $(\alpha \mathrm{t}=0.014, \alpha \mathrm{t}<0.005)$, infer the standardized regression coefficients of equation: $\mathrm{HL}=0.407 * \mathrm{IP} 1-0.367 * \mathrm{IP} 4+\mathrm{e}$

Therefore, if communication is not fluent since psychological pressures, it will be difficult to answer the unpredictable questions of interviewers. That completely was the reason why candidates were rejected.

\subsubsection{Importance of work experience}

Table 4. Frequency table

\section{RR5}

Cumulative

Frequency Percent Valid Percent Percent

\begin{tabular}{llllll}
\hline Valid & Yes & 29 & 23.2 & 23.2 & 23.2 \\
\cline { 2 - 5 } No & 96 & 76.8 & 76.8 & 100.0 \\
\hline Total & 125 & 100.0 & 100.0 & \\
\hline
\end{tabular}

\section{RR6}

Cumulative

Frequency Percent Valid Percent Percent

\begin{tabular}{llllll}
\hline Valid & Yes & 15 & 12.0 & 12.0 & 12.0 \\
\hline
\end{tabular}


Table 4 depicts the number of candidates who were rejected from a job interview because of not enough work experience (RR5) and lack of academic knowledge (RR6). The data shows the percentage of candidates being rejected because of lack of work experience $(23.2 \%)$ is more than twice as likely to be due to lack of academic knowledge (12\%). As a result, organizations place a higher value on work experience than on degree and doctrinaire in requirement and selection. All of them prioritize the selection of candidates with extensive work experience. This selection greatly shortens the training process for new employees.

Table 5. Correlations

\begin{tabular}{|c|c|c|c|c|}
\hline & & PS & RR5 & RR6 \\
\hline \multirow[t]{3}{*}{ PS } & Pearson Correlation & 1 & $.438^{* *}$ & .092 \\
\hline & Sig. (2-tailed) & & .000 & .306 \\
\hline & $\mathrm{N}$ & 125 & 125 & 125 \\
\hline \multirow[t]{3}{*}{ RR5 } & Pearson Correlation & $.438^{* *}$ & 1 & -.088 \\
\hline & Sig. (2-tailed) & .000 & & .330 \\
\hline & $\mathrm{N}$ & 125 & 125 & 125 \\
\hline \multirow[t]{3}{*}{ RR6 } & Pearson Correlation & .092 & -.088 & 1 \\
\hline & Sig. (2-tailed) & .306 & .330 & \\
\hline & $\mathrm{N}$ & 125 & 125 & 125 \\
\hline
\end{tabular}

**. Correlation is significant at the 0.01 level (2-tailed).

The interviewers tend not to select candidates because of not enough work experience. Comparing the data from Table 5, the correlation coefficient of the number of university students who were eliminated for lack of work experience (RR5) is higher than for lack of academic knowledge (RR6) because of Sig. $(R R 5)=0.000$; Sig. $($ RR6) $=0.306 ; 0.000<0.306$ and Pearson Correlation (PS;RR5) $\mathrm{r}=0.438^{* *}$. If you choose experienced candidates, employers will not need to spend time training them. 
4.1.4 The essential role of Curriculum Vitae (CV)

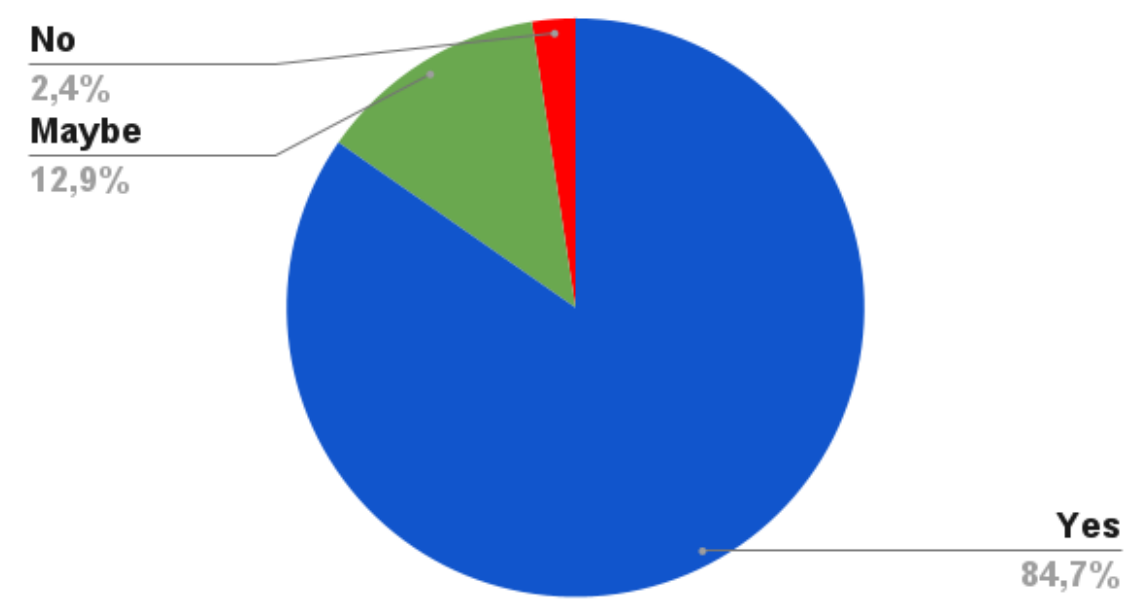

Figure 3. The necessity and importance of $\mathrm{CV}$ in the recruitment

Figure 3 illustrated $83.7 \%$ of candidates that had designed CVs before the job interview took place. In addition, the impressive level of the $\mathrm{CV}$ in the recruitment is estimated through a histogram in Table 6 . The rating scale ranges from 1 to 5, equivalent to the following levels: very low; low; medium; high; very high. The highest coefficient falls on the 3rd level (Medium) and is followed by the fourth (High). As a result, the CV plays an essential role in recruitment, and a poor $\mathrm{CV}$ affects candidates to receive lower interview performance ratings.

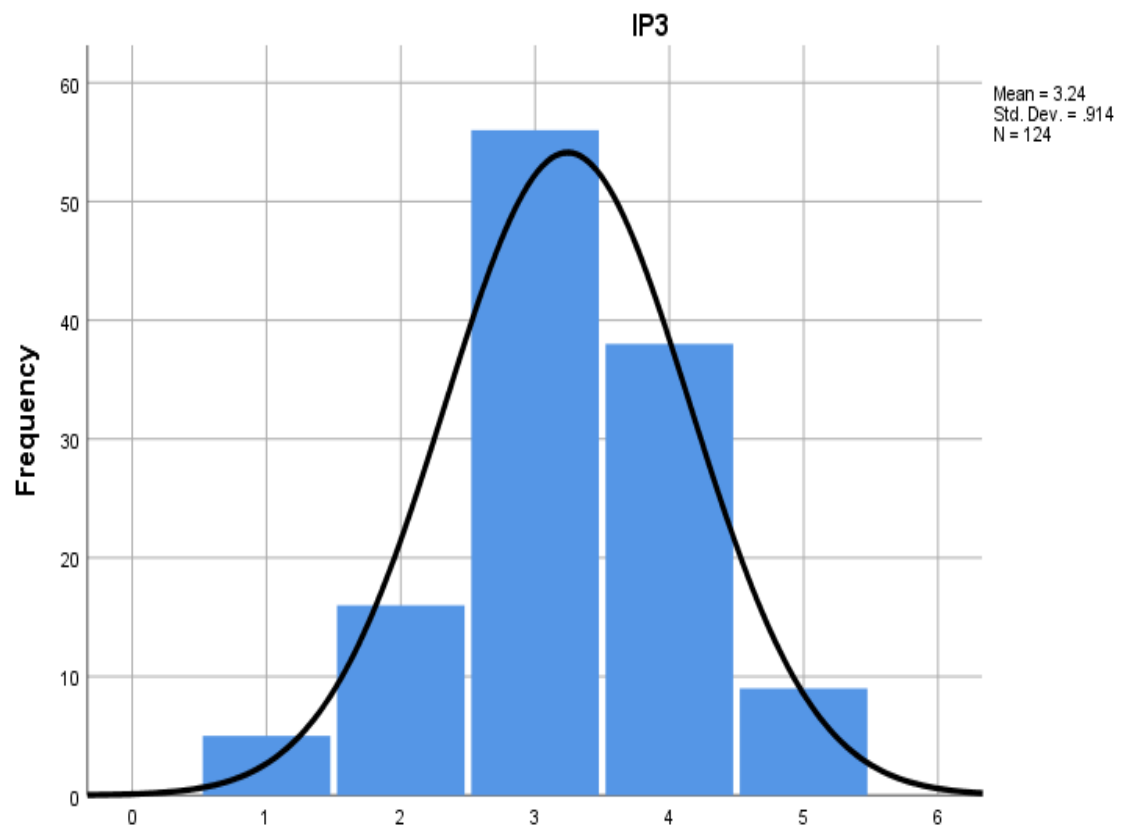

Table 6. The impact of relationships in a job interview 


\subsubsection{The impact of relationships}

Table 7. The impact of relationships in a job interview

\begin{tabular}{l|l} 
Frequency Percent $\quad$ Valid Percent Percent \\
\hline
\end{tabular}

\begin{tabular}{|c|c|c|c|c|c|}
\hline \multirow[t]{4}{*}{ Valid } & Agree & 66 & 52.8 & 53.2 & 53.2 \\
\hline & Disagree & 30 & 24.0 & 24.2 & 77.4 \\
\hline & Maybe & 28 & 22.4 & 22.6 & 100.0 \\
\hline & Total & 124 & 99.2 & 100.0 & \\
\hline Missing & System & 1 & .8 & & \\
\hline Total & & 125 & 100.0 & & \\
\hline
\end{tabular}

From Table 7, the number of candidates who agree that relationships directly affect whether they are recruited or not accounted for more than fifty percent (53.2\%). Furthermore, more than a fifth of them replied "Maybe" in questionnaires. Statistics have denoted if the candidates have many relationships or extensive acquaintance, the interview performance ratings of they receive are higher. Applying for a job through relationships is a painful situation in Ho Chi Minh City in particular and Vietnam in general. It can be said that this is unfair to candidates with real abilities and qualifications.

\subsection{Discussions}

Besides the past research, the results of the present survey have found new realistic challenges. The results of the past discovered that psychological pressures are the most significant challenges that lead candidates to receive lower interview performance ratings (McCarthy \& Goffin, 2004) (Feiler \& Powell, 2015) (Heimberg, et al., 1986). These researches also determined psychological expression during the job interview: anxiety, weak knees, sweaty palms, speech rate (words spoken per minute). The present survey dug for these results and synthesized new outcomes. The voice is also influenced by psychological pressures, impeding the ability to answer questions of interviewers. For example, this influence increases the vibration in the voice and reduces the ability to react to unpredictable questions. Of course, hesitation is inevitable.

The above statistics analyzed the importance of $\mathrm{CV}$, work experience, and relationships in the job interview process in Ho Chi Minh City. But of course, candidates with good qualifications in some fields such as accounting (Nghi, 2011), language skills, customer service, marketing, etc., can take up many important positions in the business. It is completely consistent with past researches. An outstanding point that has rarely been mentioned before is the impact of relationships in recruitment and selection. Candidates were based on acquaintances to search for jobs and advance the selection rate. This injustice also decreases interview performance ratings of other candidates who complete for job vacancies.

At first, the author intended to analyze the impacts of gender and physical on the job 
application process. However, collected raw data is not enough for an analysis. The limitation of this survey lies in the method of data collection that is only the questionnaires cannot get all necessary information from the participants. Future researches may incorporate other data collection methods such as organize actual interviews more closely.

\section{Conclusion}

Enterprises are increasingly strict in the recruitment process, besides the competition of human resources. The ultimate purpose of this survey is to help the candidates identify their problems to improve and overcome in order to receive higher interview performance ratings. The above statistics have summarized five significant conclusions. Firstly, this survey has found the biggest problem that candidates in Ho Chi Minh City face during the interview is psychological pressure. Secondly, psychological instability increases the vibration in the voice and reduces the ability to react to unpredictable questions, impeding inevitable hesitancy. Thirdly, candidates with long-term work experience have more advantages in selections. Curriculum vitae (CV) play a decisive role in the interviewers' evaluation process. And the final result proclaims candidates will be appreciated if they have a lot of relationships or acquaintances. The limitation of this survey is the method of data collection. Other methods of information collection, such as conducting realistic interviews or collecting CVs, can be used in future studies to analyze the new aspects more profoundly.

\section{Acknowledgments}

As the completion of this survey, the author expresses my deepest appreciation to survey supervisor Mr. Tran Tin Nghi, Faculty of Languages, Ho Chi Minh City University Food Industry providing all the necessary guidance and patience in evaluation. His simple but clear writing style, which is something I hope to learn from throughout my career. Special thanks to the participants who took their time to survey the questionnaires. Their contribution is a core part of conducting a smooth survey and actual data formation. Acknowledge experienced scholars for reading and giving good pieces of advice. Thank you for everything.

\section{Appendix}

Survey Question for investigating the challenges of applying for a job.

1. Your email:

2. Full name:

3. Your gender: A. male

B. female

C. other

4. Your current position: A. university students B. Graduates/ service professionals

5. Your major/ profession: Select from the list

6. Have you had problems attending a job interview? A. yes B. no

7. Impression level of employers on candidates in job interviews:

1. Confidence: A. very low $\quad$ B. low $\quad$ C. medium $\quad$ D. high $\quad$ E. very high

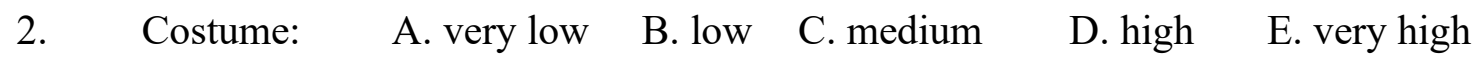

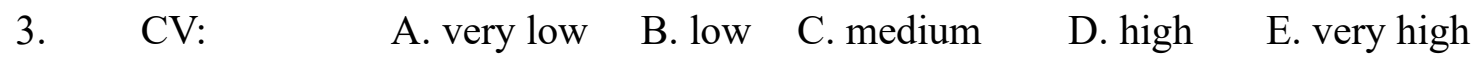

4. Ability to answer questions: 

A. very low
B. low
C. medium
D. high
E. very high
5. Punctually:
A. very low
B. low
C. medium
D. high
E. very high
6. Gesture:
A. very low
B. low
C. medium
D. high
E. very high

8. What are the factors that worry you during the job interview? (select from the list)
A. psychological pressure
B. the unpredictable questions of interviewers
C. the high criteria of interviewers
D. the voice
E. inexperienced
F. lack of academic knowledge
9. In your opinion, is the CV necessary and crucial in impressing employers?
A. yes
B. no
C. maybe

10. In your profession, what is the most crucial standard that employers evaluate and select candidates?
A. experience
B. ability
C. academic knowledge
D. certificate
E. communication skills/ language skills
F. pressure resistance ability
G. Teamwork H. relationships
11. Share a reason why you failed a job interview? Select from the list.

\section{References}

Behrend, T., Toaddy, S., Thompson, L. F., \& Sharek, D. J. (2012, 11). The effects of avatar appearance on interviewer ratings in virtual employment interviews. Computers in Human Behavior, 28(6), 21282133. doi:https://doi.org/10.1016/j.chb.2012.06.017

Feiler, A. R., \& \& Powell, D. M. (2013). Interview anxiety across the sexes: Support for the sex-linked anxiety coping theory: Personality and Individual Differences.

Feiler, A. R., \& Powell, D. M. (2015, 04 02). Behavioral Expression of Job Interview Anxiety. Journal of Business and Psychology, 31, 155-171. doi:https://doi.org/10.1007/s10869-015-9403-z

Forsythe, S., Drake, M. F., \& Cox, C. E. (1985). Influence of Applicant's Dress on Interviewer's Selection $\begin{array}{llll}\text { Decisions. Journal of Applied Psychology, 70(2), 374-378. } & \text {. }\end{array}$ doi:https://psycnet.apa.org/doi/10.1037/0021-9010.70.2.374

Hall, C., Wildgen, J. S., \& Sherman, J. A. (1980). Teaching job interview skills to retarded clients. (L. LeBlanc, L. B. Consulting, \& U. o. Kansas, Eds.) Journal of Applied Behavior Analysis, 13(3), 433-442. doi:https://doi.org/10.1901/jaba.1980.13-433

Heimberg, G., R., Keller, E., K., Peca-Baker, \& A., T. (1986, 4). Cognitive assessment of social-evaluative anxiety in the job interview: Job Interview Self-Statement Schedule. Journal of Counseling Psychology, 33(2), 190-195.

McCarthy, J., \& Goffin, R. (2004, 09 16). MEASURING JOB INTERVIEW ANXIETY:BEYOND WEAK KNEES AND SWEATY PALMS. (B. Erdogan, Ed.) Personnel Psychology, 57(3), 607-637. doi:https://doi.org/10.1111/j.1744-6570.2004.00002.x

Nghi, T. T. (2011). English for Accounting. Ho Chi Minh: NXB Giáo Dục Việt Nam.

Piopiunik, Marc; Schwerdt, Guido; Simon, Lisa; Ludger Woessmann. (2018, 2 23). CV elements that will get you a job interview. Retrieved from VOXeu, CEPR: https://voxeu.org/article/cv-elements-willget-you-job-interview

Schawbel, D. (2012, 09 27). Why Recruiting Is Vital to Your Success? Retrieved from American Express: https://www.americanexpress.com/en-us/business/trends-and-insights/articles/why-recruiting-is- 
the-most-important-hr-function/

Sieverding, M. (2009, 11 12). 'Be Cool!': Emotional costs of hiding feelings in a job interview. (I. Nikolaou, Ed.) International Journal of Selection and Assessment, 17(4), 391-401. doi:https://doi.org/10.1111/j.1468-2389.2009.00481.x

Spinks, N., \& Wells, B. (1999, 2 1). Trends in the employment process: résumés and job application letters. Career Development International, 4(1), 40-45. doi:https://doi.org/10.1108/13620439910249953

Strack, R., Kotsis, Á., Kaufman, E., Sigelman, M., Restuccia, D., \& Taska, B. (2019, 9 12). What's Trending in Jobs and Skills. Boston, Massachusetts: Boston Consulting Group.

Wolfgang, A. (2016, 03 08). Why Is It So Hard to Find a Job? Retrieved from Coaching 4good: https://coaching4good.com/why-is-it-so-hard-to-find-a-job/ 